\title{
Assessing trainee's profile for better adoption of home science practices
}

\author{
Sandeep Kaur and Sukhdeep Kaur Mann
}

Received: 27.02.2020; Revised: 30.03.2020; Accepted: 15.05.2020

See end of the paper for authors' affiliations Sandeep Kaur

Department of Extension Education and Communication

Management, Punjab Agricultura University, Ludhiana (Punjab) India

Email : sandeepbhullar586@ gmail.com
ABSTRACT : The present investigation was conducted to assess trainee's profile for better adoption of home science practices. The study was conducted in purposively selected Rauwal, Sidhwan Kalan, Talwandi Khurd and Sarabha villages of Ludhiana district, where RAWE (Rural Awareness Work Experience) programme was conducted during the year 2013-14 to 2016-17. From each village, thirty rural women who were exposed to home science practices during RAWE were randomly selected. Thus, a total of 120 respondents constituted the sample of the study. Data were collected through a well structured and pre tested interview schedule. The results of the study showed positive and significant relation between the educational qualification, land holding, annual income of family and mass media usage. However, age was negatively and significantly associated with adoption status of practices. Practices should be need based and cost effective and students should be trained properly before RAWE were the major suggestions given by the respondents for improvement in RAWE programme.

KEY WORDS: Rural Awareness Work experience, Adoption, Home science practices, Trainees

- HOW TO CITE THIS PAPER : Kaur, Sandeep and Mann, Sukhdeep Kaur (2020). Assessing trainee's profile for better adoption of home science practices. Asian J. Home Sci., 15 (1) : 138-142, DOI: 10.15740/ HAS/AJHS/15.1/138-142. Copyright@ 2020: Hind Agri-Horticultural Society. 